This item was submitted to Loughborough's Research Repository by the author.

Items in Figshare are protected by copyright, with all rights reserved, unless otherwise indicated.

\title{
Re-reading discourse and social psychology: transforming social psychology
}

PLEASE CITE THE PUBLISHED VERSION

http://dx.doi.org/10.1111/j.2044-8309.2011.02085.x

\section{PUBLISHER}

Wiley-Blackwell @ The British Psychological Society

\section{VERSION}

AM (Accepted Manuscript)

\section{LICENCE}

CC BY-NC-ND 4.0

\section{REPOSITORY RECORD}

Potter, Jonathan. 2019. "Re-reading Discourse and Social Psychology: Transforming Social Psychology". figshare. https://hdl.handle.net/2134/15124. 
This item was submitted to Loughborough's Institutional Repository (https://dspace.lboro.ac.uk/) by the author and is made available under the following Creative Commons Licence conditions.

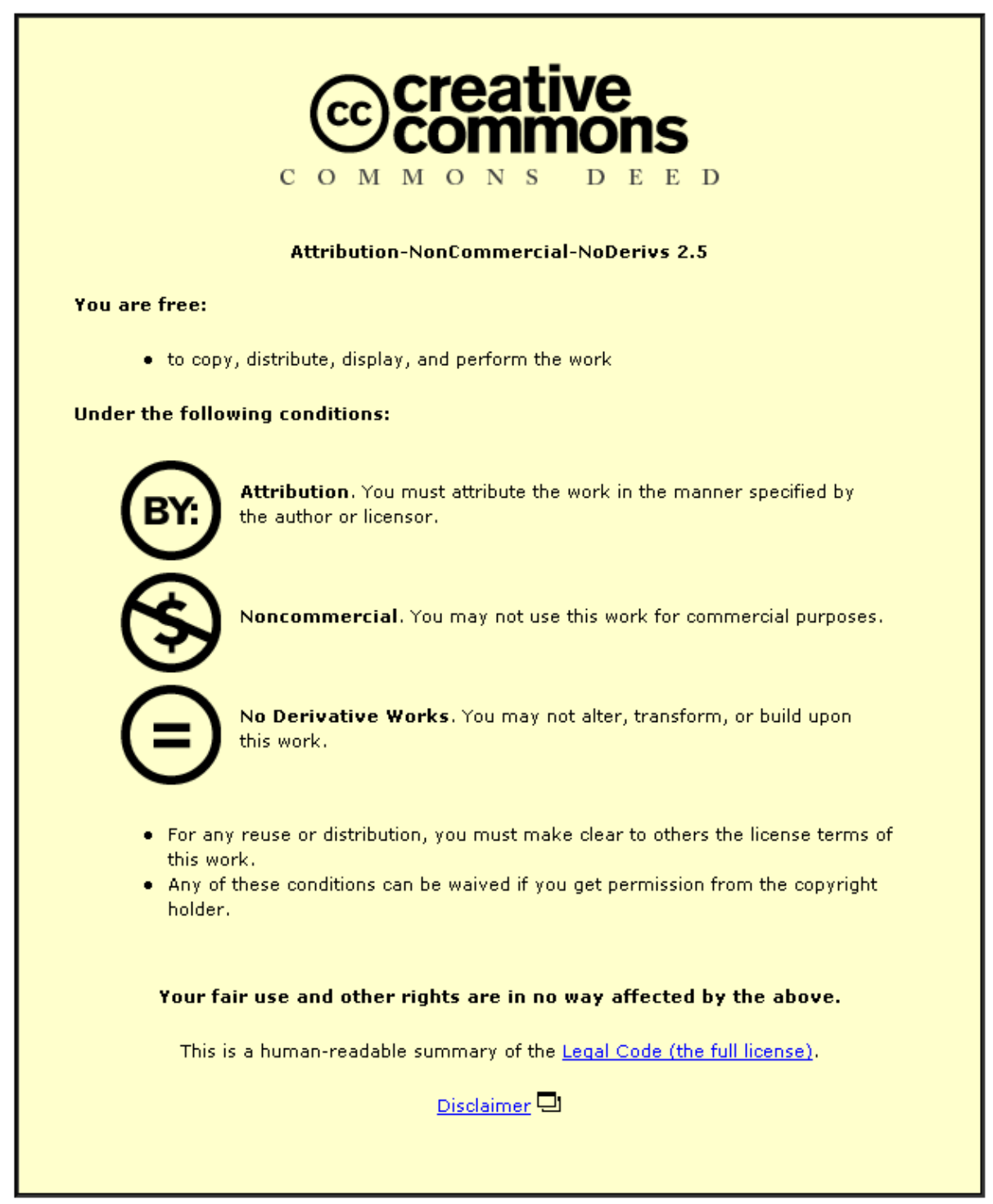

For the full text of this licence, please go to: http://creativecommons.org/licenses/by-nc-nd/2.5/ 


\section{Published as:}

Potter, J. (2012). Re-reading Discourse and Social

Psychology: Transforming social psychology, British

Journal of Social Psychology 51, 436-455.

\section{Rereading Discourse and Social Psychology: Transforming social}

\section{psychology?}

\section{Jonathan Potter}

Discourse and Rhetoric Group

Department of Social Sciences

Loughborough University

Loughborough

Leicestershire, LE11 3TU

I would like to thank Michael Billig, Derek Edwards, Dave Elder-Vass, Alexa Hepburn and Liz Stokoe for comments on an earlier draft of this paper. I hope that Tony Manstead will forgive my use of his chapter as an example; I am well aware that he is broadminded and sophisticated researcher with a strong respect for alternative approaches.

Keywords: discourse analysis, social psychology, methods, interviews, conversation analysis, theory, emotion, causality, practices

\footnotetext{
* Requests for reprints should be addressed to Jonathan Potter, School of Social, Political and Geographical Sciences, Loughborough University, Loughborough, Leicestershire, LE11 3TU, UK (e-mail: J.A.Potter@lboro.ac.uk).
} 


\section{Abstract}

This paper considers one theme in the contemporary legacy of Potter and Wetherell's (1987) Discourse and Social Psychology. It overviews the context that led to that book and considers a series of critical responses from both experimental and critical/qualitative social psychologists. It refutes criticisms and corrects confusions. Focusing on contemporary discursive psychology, it highlights (a) its rigorous use of records of actual behaviour; (b) its systematic focus on normative practices. In methodological terms it (a) highlights limitations in the use of open ended interviews; (b) considers the way naturalistic materials provide access to participants' own orientations and displays; (c) builds a distinctive logic of sampling and generalization. In theoretical terms it (a) highlights the way discourse work can identify foundational psychological matters; (b) offers a novel approach to emotion and embodiment; (c) starts to build a matrix of dimensions which are central to the building and recognizing of different kinds of social actions. It now offers a fully formed alternative social psychology which coordinates theory and method and a growing body of empirical work. 


\section{THE CONTEXT OF DISCOURSE AND SOCIAL PSYCHOLOGY}

In the early 1980s while the ideas that were formed into Discourse and Social Psychology (Potter \& Wetherell, 1987) were being developed, social psychology in both the UK and North America was overwhelmingly based on experimental or questionnaire studies, most of them conducted on college students. At that time there were very few general texts on 'qualitative methods' in social science generally, and none in psychology. There was no use of open ended interviews in psychology - although they were being used in ethnographic work in sociology and anthropology. There was no research using direct naturalistic records of interaction, although the use of indirect observational methods had been haltingly explored (Barker, 1968; Webb et al., 1966).

A so-called 'crisis in social psychology' had smouldered through the 1970s. In North America the crisis focused on method and particularly the damaging role of 'demand characteristics', 'experimenter effects', the limited 'external validity' of laboratory experiments, and the difficulty of separating experimental findings from historical and cultural contexts (e.g. Elms, 1975; Gergen, 1973; McGuire, 1973). Self styled ‘European social psychology' supplemented these problems by highlighting the individualism of much social psychological research, its failure to adequately fit social psychological analysis to a broader social and political analysis, and its inadequate notions of causality (e.g. Harré \& Secord, 1972; Israel \& Tajfel, 1972; Shotter, 1977). The diagnosis and critique was in many ways brilliant and generated much debate. Yet it did not offer a fully realised research alternative to traditional approaches to social psychology. Rom Harré's (1979) 'ethogenic' perspective came closest to this, but did not build a sustained body of research studies. 
The success of Discourse and Social Psychology is at least partly due to its provision of a novel vision of how research might be done.

It was influenced by post-structuralist thinking (particularly the work of Roland Barthes and Michel Foucault). Such work had been earlier introduced into British psychology via the short lived journal Ideology and Consciousness in the late 1970s and developed into a full perspective in the Changing the Subject (Henriques, et al., 1984/1998). The engagement of Discourse and Social Psychology with post-structuralism, however, came out of separate exploration which compared literary and social psychological constructions of human action (Potter, Stringer \& Wetherell, 1984). Post-structuralism offered tools for understanding the way language and meaning operated in social practices, and in particular the complex constructive business done by ostensively straight descriptions, and it continues to be central in more ideological streams of discourse work (Wetherell, 1998, in press).

At least as important as post-structuralism was an engagement with conversation analysis, ethnomethodology and linguistic philosophy (Coulter, 1979) and the sociology of scientific knowledge (itself stimulated by radical developments in philosophy of science derived from Popper, Kuhn and Feyerabend). Indeed, the version of discourse analysis drawn on in Discourse and Social Psychology did not come from linguistics (where there were already at least two analytic approaches called discourse analysis) but from Nigel Gilbert and Michael Mulkay's discourse analytic approach to the sociology of scientific knowledge (Gilbert \& Mulkay, 1984 - see Mulkay, Potter \& Yearley, 1983, for an early statement). This introduced the notion of an 'interpretative repertoire' to describe the different kinds of accounts that scientists offered when they were justifying their own 
claims and explaining away the claims of competitors. A refined version of this became a central analytic tool in Discourse and Social Psychology.

Although Discourse and Social Psychology engaged with theory, meta-theory and philosophy, it was distinctive in building its argument for a new way of doing social psychology on detailed, concrete analysis of actual discourse. As we will see, this distinctive, empirically driven, element in discourse analysis has sometimes been missed by critics working within social psychology who have focused on its constructionist or antifoundationalist themes and have not appreciated how far this constructionism was married with careful empirical work on texts and talk (Potter, 1996). Some of chapters worked with open ended interviews, others primarily reworked analyses of real-life materials from everyday or institutional settings. Conversation analytic work was drawn heavily on for the analysis of mundane telephone calls, police interrogations and courtroom interaction; all records of interaction that would now be called 'naturalistic materials'. The natural is to mark the contrast from the 'got up' materials that have been at the centre of social psychology's development in North America and much of Europe - vignettes, experimental protocols, survey responses - while natural is qualified as naturalistic to highlight a sophisticated awareness of the potential for researcher involvement in such material (Potter, 2002, in press).

Discourse and Social Psychology offered a complete approach to social psychological matters. It took the chapter headings of the textbooks of the time - attitudes, categories and so on - and developed alternative analyses that often completely rebuilt the original notions. The aim of this paper is to offer something of an audit of the coherence and success of one major strand of discursive psychology after more than a quarter of a century. A full description of the different strands of this work is beyond the scope of this paper, let 
alone a full evaluation. Part of the problem here is that discourse work has been evolving with different emphases and as parts of different debates over this quarter century, and the different critical responses have a range of specific targets. Inevitably this audit of arguments and issues will engage in considerable simplification.

In simple terms, Discourse and Social Psychology had a major impact across the social and human sciences - more than four thousand citations in more than two hundred and fifty different journals. This impact has gradually built up such that in 2011 the annual rate of citation in journals, books and chapters is more than five hundred a year. It helped establish some form of discourse analysis as a component of social psychology and social sciences more generally, it offered new ways of working with open-ended interviews, and it helped establish the legitimacy of using qualitative methods in psychology. Nevertheless its coverage in North America and APA journals is limited. By adopting a story of science as only conducted through experiments, these journals have effectively operated a closed shop against radical alternatives or debates. Despite the more sophisticated understanding of the history and philosophy of science that is widely available the system has remained closed; there is an important argument to be had.

The rest of this paper will consider a series of topics. These are mostly organized around problems with common criticisms of discourse work. It will outline current thinking, respond to criticisms and, where necessary, indicate limitations in the original work. The aim will be to offer a set of observations that mesh together to provide a complete picture of a discursive social psychology that can provide an alternative to both traditional and critical contemporary perspectives.

These debates are organized around two very different visions of human conduct and its study. The majority of contemporary approaches treat human conduct as ultimately 
dependent on putative individual entities such as beliefs, attitudes and knowledge. Approaches as varied as social cognition (Fiske \& Taylor, 2008) and interpretative phenomenological analysis (Smith \& Osborne, 1998) have adopted some version of this cognitivism. Discourse psychologists start with practices; that is, people interacting with one another, in mundane and institutional settings; and they bracket off issues of cognition. It is not that discursive psychologists do not consider thinking, cognition, mind, feelings and so on, but this is not something they start with and they see as the causal underpinning of social behaviour. Rather these things become a major topic of analysis in terms of the orientations and constructions of participants.

\section{SCIENCE}

Anthony Manstead's (2008) authoritative chapter on methods of social psychology engages, briefly but consequentially, with discourse work to justify not including it in the book. It is a useful start point because it makes explicit arguments that have been expressed in other publications and more informally expressed in talks and conferences. It captures what might be called the mainstream response to discourse work. It provides a set of reasons why this large body of work should be excluded from social psychology. It is a condensed piece of academic gatekeeping. Given this consequence it will be worth considering the logic and rationale for this exclusion carefully.

Manstead spends a paragraph overviewing one of the first discourse analytic publications in the BJSP (Wetherell, Stiven \& Potter, 1987) and then writes: 
This sort of qualitative approach is not represented in the present volume, where the emphasis is on the strengths of a realist, quantifiable social psychology. This is not to say that qualitative methods play no role in the research that is represented in this book. It is more that, as noted above, qualitative methods are used in the early stages of such research, rather than being the sole research method. The role played by qualitative research methods in social psychology largely reflects differences in philosophical belief about the causation of social behaviour. For realist social psychologists, social behaviour has causes, and the goal of research is to shed light on those causes. For many qualitative researchers, social behaviour does not have causes in the same way that, say, an earthquake has causes. Such researchers use qualitative research methods to identify how people construct their own an others' behaviours. From the standpoint of the research represented in the present volume, qualitative research seems to be more focused on description than explanation, and more concerned with how behaviour is constructed than how it is caused (Manstead, 2008).

Two initial observations: first, this quote combines large bodies of work together using the conventional yet problematic distinction between quantitative and qualitative research. From the perspective of contemporary discourse work numbers are not the issue (discursive psychology and, indeed, contemporary conversation analysis is increasingly using quantification of different kinds). As noted above, a more relevant distinction is between work that presupposed some form of cognitivism and work that does not (Edwards \& Potter, 2005). In the quote above, using a cognitivist metatheory comes close to being equated with doing science itself - this is a form of rhetorical gerrymandering that will need unpacking.

Second, it builds a picture of qualitative research as something focused primarily on description rather than explanation, and therefore something that should be done as a preliminary phase in research before it matures to full quantification. More on this below, 
but just note that although this idea of the qualitative preliminary to mature work is a regular trope in the history of social psychology, but it is far from clear that experimental studies do start with such a phase of work, and if they did what its systematic basis would be, how it would be related to the experimental protocols used, and so on. For example, in reviewing experimental social psychological work on threats Jonathan Potter and Alexa Hepburn (2011a) found no evidence of descriptive phase of work; the conceptualization of threats was truncated and presumptive. It is hard to escape the view that the idea of a preliminary qualitative phase to quantitative research is more rhetorical than genuine. a For researchers who have done considerable descriptive work and have come to recognize the difficulty and subtlety involved in collecting material, developing appropriate analytic categories, and managing it systematically, the idea that there is a regular early phase in experimental work that is nevertheless invisible in the published literature is simply not credible. Long before Discourse and Social Psychology was published Henri Tajfel (1972) bemoaned the prevalence of 'experiments in a vacuum'; the contemporary failure to embed experimental work in careful descriptive studies is surely more of the same.

\section{I-Observation and empiricism}

Discourse and Social Psychology was partly a sketch of a different kind of observational, empirical science of human social life. It had a sophisticated take on what it was to make observations, based in the critique of simple empiricism developed in different ways by Imre Lakatos, Thomas Kuhn and Karl Popper (see Godfrey-Smith, 2003). But at its centre was systematic focus on the organization of participants' discourse. Such observation threw up findings that immediately sat in contrast with standard social psychological assumptions. For example, if you looked carefully at the talk of individuals 
they would move between a range different evaluative positions on a particular object. As Chapter Two of Discourse and Social Psychology demonstrated, the variability inevitably thrown up by the practical and situated nature of evaluative actions was mostly ironed out by the operational procedures of attitude scales and the way they are statistically processed (Potter, 1998). However carefully you search the literature that satisfies Manstead's criterion of scientific social psychology you will not find careful descriptive work on the way attitudes appear in everyday settings.

In Karin Knorr-Cetina's (1999) study of the work of high energy physicists with at CERN she found something striking about the way they divided their time. The physicists spent more time describing and understanding the operation of the particle detector than they spent in full research operations aimed at identifying particles and testing theories. The reason for this is simple; the physicists were not sure what they were how to interpret the trails and numbers without a very full understanding of the detector and its vicissitudes.

There is a telling comparison here with social psychology. In the research literature on social psychology there is very little analytically grounded discussion of how social psychology experiments work. This may be because experimental social psychologists believe that their participant experience of experiments gives them sufficient access such that no better understanding is needed. However, that is not their characteristic stance on other areas of social life. Moreover, being able to take part in a culture is quite different from being able to describe it in a way that communicates precisely to others in a way that explicates its operation. It may be that social psychologists simply do not have the systematic theoretical and analytic apparatus for studying a complex, unfolding social institution such as a social psychology experiment. If that is the case, then that is something that might give them pause for thought. Finally, it may suit social psychologists to not have 
such an interest as there is so much invested in the success of the experiment as a tool for social psychology research. If it is experiments that are the key bastion against the encroachment of discourse researchers then it might be safer not to ask uncomfortable questions.

In this context, it is interesting to look at descriptions of how the crisis was resolved (see Manstead, 2008, pp. 14-16). It is surely time for a collaboration between an experimental social psychologist, a discursive psychologist and a sociologist of science in studying how a social psychology experiment is conceived, performed, analysed, and reported. This might bring experimental social psychologists a little closer to high energy physicists.

It is important to stress that the situation is no better for qualitative social psychology in traditions such as social representations or interpretative phenomenological analysis. There is a tiny metaliterature on the open ended research interview. Given that the interview is the principal means through which much qualitative research generates its data it is clearly equally deserving of a systematic research study. Indeed, discursive psychologists have initiated such a study - more on this below.

\section{II - Experiments and causality}

In Manstead's (2008) gatekeeping statement he makes a contrast between a concern with how behaviour is constructed and a concern with how it is caused. This might seem a clear epistemic distinction. Scientists can enter here; constructionists and literary critics have their own nicely decorated clubs further down the street. However, this perpetrates a number of confusions about discourse work and depends on a problematic picture of science. In particular, it blurs together the anti-foundationalist meta-theory most 
controversially developed in Death and Furniture (Edwards, Ashmore \& Potter, 1995) with the kinds of insights in Discourse and Social Psychology and later Wetherell and Potter (1992) about the role of descriptions in the management of racist critique. Death and Furniture was not a foppish manifesto for a world without foundations; it was a contribution to epistemic thinking that drew on sociology of scientific knowledge and discursive psychology to highlight a generic epistemic predicament of research in physics, social psychology of all kinds, legal cases, police interrogations and relationship disputes. One can argue against the position (e.g. see Elder Vass, in press), but it is a mistake to see it as reflecting a research choice that can simply be made differently. Discursive psychologists haven not voted for an anti-foundationalist epistemology; rather, they have arrived at such a position through conceptual and historical analysis. Moreover, the anti-foundationalism is not relevant to much of its basic analytic practice. Like scientists of all kind there is a concern with rigour, clarity, the quality of empirical data, the systematic basis of analysis and so on. There is virtually no reference to constructionism in Discourse and Social Psychology. Ken Gergen's (1985) treatise on social constructionism had been published, and this referred back to Peter Berger and Thomas Luckmann's (1966) classic, but the breadth and complexity of constructionist thinking was not yet apparent (see papers in Holstein and Gubrium, 2008). Potter (1996) was partly an attempt to clarify what it is at stake. It wrests constructionism from Berger and Luckmann's cognitivist picture and avoids the emphasis on narrative that is central to Gergen's work (e.g. Gergen, 2009; for the arguments that urge caution about the notion of narrative see Edwards, 1997, ch. 10); instead, it focuses on the careful empirical study of how descriptions are formed to produce and manage particular actions (blaming, accounts, attacks and so on). Construction is here something concrete and analytically tractable in line with the programmatic emphasis of Discourse and Social 
Psychology. For example, Derek Edwards and Jonathan Potter's (1993) engagement with attribution theory highlighted the central role of descriptions in forming attributions, and showed how this is available for systematic, public, reproducible study.

Manstead's (2008) contrasts construction with causation. Causation sounds like a golden ticket for membership of the scientific social psychology club. However, it dissolves under careful scrutiny. First, controlled experiments are certainly claimed to identify effects beyond mere associations. Yet, such effects can be a consequence of conceptual relationships; the separation out of variables does not establish the precise mechanism of the operation of those variables. The figuration of the term 'effect' suggests a mechanical impulsion but a significant 'effect' found using a test such as an ANOVA does not prove anything so mechanical. For example, if studies show that social influence is a consequence of information that is treated as reliable, that does not specify precisely how information is involved in changes in conduct. The relentless focus on experimental relationships divorced from any serious study of interactional process or conduct encourages a billiard ball vision of causation (an argument that Rom Harré made effectively and repeatedly; e.g. Harré 1979). However, the identification of relationships in experiments surely raises the question of what makes them come about. A cognitivist answer to this question will lead to further focus on processing and then on to social neuroscience. Yet that fails to consider the normative order of interaction within which conduct ('behaviour') is situated. Discursive psychology highlights the central role of that order. Note again the discourse critique of the well known Language Category Model of attribution (Edwards \& Potter, 1993). Edwards and Potter highlight precisely some of the ways that the statistical analysis is confounded by and dependent on conceptual relations. The broader point, however, is that causality (however understood) is not the sine qua non of a scientific approach. Rather we can look to 
observation, rigour, system and prediction - things that are characteristic of contemporary discursive psychology.

Human action is contingent and voluntary. This need not be a philosophical point but reflects the normative organization of interaction which is a central and analytically tractable topic of discursive work and conversation analysis (Potter \& Edwards, in press; Schegloff, 2007). For example, requests are conventional and necessarily highly recognizable forms of action. If they cannot be recognized they will not work as requests. They do not, however, cause what happens next in the way wind might cause a tree to bend. A request sets up at least two contrasting alternatives for the recipient - granting and rejecting. These options are systematically provided for in the design of the request and typically ordered such that acceptances are 'preferred', and therefore done differently, to declinations. Indeed, requests can be designed to display increasing levels of entitlement over the actions of another and to orient to different levels of contingency of the recipient being able to grant the request (Curl \& Drew, 2008). This intricate social order is analysable in its detail and such analyses are repeatable and open to public scrutiny.

The general point here is that statistical relationships, even highly significant ones derived from experiments, need to be treated cautiously when considering what is implied by causality. Crucially, contingent relationships within action sequences are open to systematic analysis. Moreover, as Manstead notes when responding to the kinds of critical points raised in the 'crisis in social psychology', statistically significant effects may be very small. Discursive psychological work can identify clear and regular patterns, which can sometimes be in direct conflict with the claims of experimental work (see, e.g. Schmid \& Feidler, 1999; Edwards \& Potter, 1999). Ruling discourse work out on the basis of not studying 'causality' is surely based on a limited view of the processes that are amenable to 
scientific study and mixing together what is shown by a statistical experimental finding and the figuration of billiard balls and mechanical processes (Harré, 1989).

\section{METHOD}

The points above are intended to counter some of the arguments against discourse work being treated as a part of a broader tradition of empirical social psychology because of its flawed scientific status. The points below are intended to highlight the methodological coherence of a programme of discursive psychology. Again they are organized partly in relation to familiar and repeated critiques.

I- Interviews

One of the features of Discourse and Social Psychology was its introduction of a new way of working with open ended interviews. It suggested that interviews might be more effective if they were more engaged and even confrontative rather than trying to chase an impossible ideal of neutrality. Such engagement might bring into the open the varied interpretative resources ('interpretative repertoires') drawn on by participants. Rather than simply interviewing participants about their lives or beliefs the interview was intended to become an arena of ideological engagement where the different resources participants had available to manage ideological trouble could be identified and described. Such work with interviews is laborious, involving careful attention to the detail of constructions in the talk of both interviewer and interviewee. It emphasised that both parties would be drawing on ideologically live resources and the interviewees talk would need to be analysed in the context of analysis of the talk of the interviewer. The interview was conceived as an 
interactional laboratory for driving ideological resources out into the open and laying bare their organization rather than a pathway to the participants' past actions, experiences or opinions. This way of working with interviews was central to Wetherell and Potter (1992) and they have been used in similar effective ways by, for example, Billig (1992) and Augoustinos, Tuffin and Rapley (1999). For example, Tileagă's $(2005,2009,2011)$ important work on remembering, history and commemoration works with interviews and texts such as letters.

Since 1987 interviews (and sometimes focus groups) have become the default data generation method for a wide range of qualitative researchers from different perspectives in social psychology (e.g. ethnography, interpretative phenomenological analysis, narrative psychology, grounded theory, and psychoanalysis). Discourse and Social Psychology undoubtedly played its part in this proliferation. Yet as Knorr-Cetina's (1999) work showed, in other sciences there is a strong, careful reflexive attention to the operation of the machineries for data generation. This has been notably lacking with respect to interviews in social science generally and social psychology in particular. Open ended interviews present many dangerous opportunities for conducting poorly analysed research backed by illustrative quotes shorn of their interactional context (Antaki, et al., 2003; Silverman, 2011).

For some time, work in conversation analysis has focused on explicating the organization of questions and answers in a range of different institutional settings, including news interviews (e.g. Clayman \& Heritage, 2002), court rooms (e.g. Atkinson \& Drew, 1979), police interrogations (e.g. Stokoe \& Edwards, 2010), psychological assessment interviews (Antaki \& Rapley, 1996) and focus groups (Puchta \& Potter, 2002) as well as in mundane settings such as everyday phone calls and family mealtimes (Heritage \& Raymond, in press; Stivers \& Hayashi, 2010). This work highlights the extraordinary delicacy and complexity of 
questioning as a practice and the way it can embody preferences, manage neutralism, establish presuppositions and build a range of constraints that the recipient must manage (e.g. Raymond, 2003). On the one hand, this body of work highlights the bluntness of traditional notions of 'bias' and 'leading questions' in the social science methods literature. On the other, it highlights and describes the powerful role of the interviewer's questions in generating particular kinds of responses. The implications of these and other problems for qualitative work in psychology and the social sciences more broadly are profound and have been developed elsewhere (Edwards \& Stokoe, 2004; Potter \& Hepburn, 2005a,b, 2007, in press; Stokoe, 2011). They provide an important motive for discursive psychologists focusing on naturalistic materials. Ironically, although interviews were often lauded by 'qualitative researchers' as an advance over questionnaires they are in many ways similar machineries guided by the agenda of the researcher (Attenborough \& Stokoe, 2012).

\section{II - Naturalistic data and reactivity}

Many scientific enterprises have a phase or strand which focuses on description. We cannot imagine contemporary evolutionary biology without Darwin's voyage on the Beagle and his focus on small variations in the markings or structure within what were at the time considered to be distinct species. Indeed, Darwin was struck by the strong role of conventions and familiarity on the production of descriptions and how naturalists were caught up by the expectation that they would find distinct species rather than the kinds of variation that came to be seen as evidence for evolution.

In the case of social psychology, one might have expected that a major element in the scientific study of human social behaviour would be the generation of systematic observations of that social behaviour. However, for the most part such observations remain 
in the abortive field of 'ecological psychology' (Barker, 1968) or in work stimulated by the ethological study of animal behaviour (Byrne \& Whiten, 1988). It is striking that Manstead's (2008) text goes back half a century to Robert Bales (1950) Interaction Process Analysis for an example of observational research in social psychology and it is equally striking that studies of social interaction have become increasingly rare in the main North American social psychology journals in the last 30 years. One likely reason is the difficulty of reconciling the normative and voluntaristic organization of interaction with a factors and variables approach yoked to a cognitivist picture of human behaviour. The phenomenon is fighting with the method and its theoretical underpinnings. It is notable that where talk does appear in contemporary experimental work it is commonly seen as an independent variable (e.g. Pedersen and others, 2011, on rumination and Smith \& Postmes, 2011, on talk and groups).

One of the features of Discourse and Social Psychology was that it paved the way for a systematic use of records of actual human action in psychological research. Instead of making targeted observations in an attempt to test theories the aim was more to generate sustained records of particular domains - family mealtimes, say - which could be used for hypothesis generation as well as analysis. A feature of contemporary work as compared with the time of Barker or Bales is that the technology is in place for making high quality, audio and video records, on recorders that are cheap, non-intrusive, simple to use and easy to carry around. They can be given to participants to make their own recordings. Those records can be manipulated like paper transcript - edited, chopped into collections, digitally enhanced, posted, shared, and electronically anonimized.

This recording and data management technology runs alongside a form of transcription originally developed by Gail Jefferson (2004) that was developed specifically to 
capture social action. Crucially, that form of transcription is designed to capture those features of interaction that are hearably relevant for the ongoing actions for the participants. Work in conversation analysis over more than fifty years has highlighted the way that changes in pitch and speed, overlaps, emphasis and volume, combined with gesture, gaze, the use of aspiration and laughter particles, combined with different lexical selections and grammatical forms, are all potentially consequential for the unfolding conduct (Hepburn \& Bolden, in press a,b). As is common across the sciences, theory, method and descriptive categories have evolved in consort with one another (Hanson, 1958).

Note that although the order of potential relevance of these features of interaction can appear microscopic the actions that are thereby constituted need not be. The standard orthographic representation of language in novels and plays simplifies and categorizes. However, the resources for building actions are much more finely calibrated than this suggests. Analysis that loses these calibrations is not doing justice to the phenomena at hand: human action in its natural settings. Note that the relevance of these features to participants' conduct casts doubt on a range of uses of open ended interviews where research participants are expected to describe some social event or some version of conduct is generated in the form of a vignette in an experimental manipulation (Stokoe, 2011).

Sometimes social psychologists using experimental or interview techniques of data generation have complained that the collection of naturalistic material is subject to 'reactivity' that contaminates the material, and they have used this as an argument for continuing with experimental or interview work. The first thing to note here is that what reactivity there might be in discourse work is of a completely different order to the 
constraints and manipulations of experiments or the flooding of social science categories into open ended interviews (Potter \& Wetherell, 1995). Second, a range of research has been conducted on public domain materials where there is no researcher reactivity possible (e.g., in work on police interviews, recorded as endogenous practices of police procedures, rather than for overhearing researchers e.g., Stokoe, 2009), and there is little evidence of systematic differences in the areas that discursive researchers are interested. Third, letting participants record in their own settings means that there need not be the intrusive effect of the researcher's presence and this can be combined with repeated recordings that gets all parties thoroughly acclimatized to the process of recording. Jokes about being on television often appear in the first of a series of recordings, but rarely in the fifteenth. Fourth, it is possible to study those occasions where there is an orientation to the recording and consider the kinds of effects that it might have (Speer \& Hutchby, 2003; Stokoe, 2009). Indeed, precisely because records of interaction as they happen are not a black box but are closely inspectable for what is going on the very issue of reactivity is available for study. This issue is one that generates more trouble from a classic cognitivist perspective where one is concerned events, objects and processes within individuals. From an interactional perspective the focus is on organizations and practices through which the parties transact their lives with one another and these are highly resistant to faking, as studies comparing simulated and real interaction demonstrate (Stokoe, 2011a; b).

\section{III - Sampling and Generalization}

In classic experimental social psychology and a range of other social psychological work using surveys or questionnaires it is a requirement that samples are randomly selected from underlying populations. This is intended to allow the statistical generalization from 
sample to population. Discourse and Social Psychology argued for a different way of considering sampling and generalization. That picture can now be further refined. First, there is an issue of what is being sampled. In traditional work the key is typically the number of participants and whether they were representative or skewed in some way. Considerable effort is often expended in capturing specific populations - extrovert adult males, say. In discourse work, particularly that which builds on conversation analysis the aim is often to identify a normative practice.

For example, Bolden and Robinson (2011) worked through a range of different corpora of everyday conversation to identify examples where one speaker is called to account by another by way of a why interrogative. They explicate a number of subtle dimensions of this practice which is regularly an element of criticisms and challenges. Note that these researchers are not indifferent to questions of quantification. They collected 311 'why-formatted' interrogatives from 360 telephone recordings and 29 video recordings of naturally occurring English language interaction involving friends and family members. One of the features of practices of this kind is that they are normative - that is, they are necessarily widely shared otherwise they simply would not work as practices. Participants use the practice to call individuals to account, but the practice is not specific or idiosyncratic to those individuals.

That does not mean that issues of variation across groups, classes and cultures are not relevant. For example, Bolden and Robinson's analysis of English language speakers can provide a template to compare say Japanese speakers against. Maybe this practice is hard to find; maybe it is done differently, perhaps exploiting grammatical possibilities of Japanese; maybe it appears in two different forms. The core analysis provides a resource for further analysis in a stepwise manner. Moreover, we can ask whether this practice is 
exploited and perhaps refined in courtrooms or police interrogations (see, for example, Edwards, 2008, on police exploitation of mundane notions of intention in interrogations).

\section{THEORY}

It is perhaps not surprising that a work that brought the study of discourse to the fore might be treated as limited in what it can say about people. Over the last 25 years the idea that discourse work sustains an image of 'blank subjectivity' and fails to address embodiment has become common and that something else is required to get at the subtlety and 'interiority' of experience (from numerous possible examples, see e.g. Brown, et al., 2011; Parker,1997; Willig, 2001, and papers in Nightingale \& Cromby, 1999). Recently psychosocial approaches, often drawing on Lacan, and different kinds of phenomenological approaches have come to fore (e.g. Frosh \& Saville Young, 2008).

I- Experience, cognition and the 'blank subjectivity' critique

One thing that distinguishes the conversation analytic influenced strand of discursive psychology from experimental work, on the one hand, and approaches based on qualitative interviews such as the 'free association narrative method' or 'interpretative phenomenological analysis' (Hollway \& Jefferson, 2005; Smith \& Osborne, 2008) is that it puts participants own orientations at the heart of its analysis. These are the live orientations that are practical parts of conduct unfolding in real time. This is a completely different order of phenomena than the post-hoc constructions and formulations that appear in qualitative interviews. Those are a major focus for discourse work on the organization of repertoires, commonplaces and constructions that are parts of new actions 
- and they can be exploited when the research attends carefully to their role in practices in the interviews themselves (e.g. in Condor, 2006; Tileagă, 2010.

The focus on orientations in real time in natural interaction makes 'psychological' matters inescapable; such matters are an essential resource for participants as they coordinate their actions, respond to expressions of liking and dislike, say, or as they manage incipient actions such as invitations or requests. The world of discourse is psychologically imbued in precisely the way real life is imbued. The organization of discourse with its lexical items, categories, grammatical organizations and plethora of different practices is highly normative. Moreover, it unfolds in real time with an extraordinary granularity in which delays of less than a fifth of a second, or minor changes in pitch contour, can mark a 'psychological state' (Drew, 2005; Heritage, 2005). The point, of course, as Wittgenstein argued so eloquently is that psychological business is necessarily hearable/visible otherwise participants would not be able to coordinate with one another effectively (Wittgenstein, 1953: \#329; Coulter, 2008). The delicacy of this real time working of interaction is particularly difficult to capture experimentally (see Schegloff, 2004, 2006, on the insufficiency of cognitive models of dialogue), and it is a probably impossible challenge for qualitative interview based approaches.

As conversation analysis has effectively demonstrated in a cumulative empirical programme for more than fifty years, turn organization supplies a key resource for understanding other people; indeed, Schegloff has suggested that it is a major resource for sustaining intersubjectivity and the practices of conversational repair can be seen as ways of (re)accomplishing intersubjectivity when it is under threat (Schegloff, 1992). More recently, classical psychological problems of shared knowledge - who knows what and how is knowledge shared - have been tackled in subtle ways (see papers in Stivers, Mondada \& 
Steensig, 2011). Psychological matters are here studied in their home environment of live unconstrained interaction where the parties have a genuine and practical stake in outcomes (Edwards, 2006).

Far from blank subjectivity, then, the subjectivity that is live for participants is one that is voiced, expressed, sequentially organized. It is as rich as the lexical, intonational, and sequential resources of interaction can allow. This is one of the reasons for emphasising the virtues of both naturalistic materials and the careful transcription of interaction that can capture this linguistic theatre of the self (see Potter \& Hepburn, 2005a,b and responses from Hollway, Smith, and Mischler). As Billig (1999) argued, there is something problematic about those with a psychodynamic interest, for example, looking for hidden motives behind discourse and simultaneously failing to look carefully at what is actually there. Given participants treat prosody, delay, laughter and other features of delivery as crucial in their treatment of the psychological states of others, it is odd for social psychologists to argue that they do no need to take such things seriously in their materials (e.g. Hollway, 2005; Smith, 2005). Again, this emphasises how vital it is for social psychologists to systematically study the machinery that generates their findings. If researchers interview people about their experience then what is the status of this interview talk? Given that much 'cognitive' language is orientated to action, how will those actions be suppressed for mere description when talking to a social researcher? These are generic issues that were highlighted in Discourse and Social Psychology in its discussion a range of social psychological methods; but they are exaggerated with qualitative research interviews about 'experience' (Potter, in press).

\section{Feeling and emotion}


Emotion was hardly mentioned in Discourse and Social Psychology. At that time emotion had typically been constructed as associated with physiology and something having a causal and often distorting effect on cognition. Critics of discourse work have not been slow to flag emotion as a topic of study beyond the mere analysis of talk and text. Since the 1980s, however, discourse researchers have started to address emotion, although that, in turn, has involved considerable caution about the category 'emotion' itself. As Edwards argues, emotions are shifting and complex notions which different boundaries and contrasts within different cultures and settings:

Emotions are not only contrasted with cognitions (whether rational or not), both in 'folk' and in professional psychology, but there are also cognitive theories of emotions, and indeed cognitive models that virtually do away with, or explain away, emotion categories altogether. But there are also emotion-based explanations of cognition, of what people think, what they think about, and why they think one thing rather than another (because of envy, jealousy, prejudice, obsession, etc.) (1999, pp. $\left.{ }^{* \star}\right)$.

Indeed, a common limitation of classic psychological work on emotions was to presuppose emotion categories of common English language groups and compare other cultures with that template (Edwards, 1997). This has become the basis for research on (a) the use of 'emotion' categories; (b) orientations to objects and actions as 'emotional' and (c) displays and receipts of 'emotion' (Edwards, 2007).

The original theoretical reformulations of Discourse and Social Psychology have led to work moving in very different directions. On the one hand, the kinds of painstaking descriptive study of the way crying and upset are displayed in talk has highlighted the extraordinary delicate orientations of participants to possible trouble. Hepburn (2004) showed that call takers on a child protection helpline were able to use small fragments of tremulous delivery, combined with placing in topic talk, and small changes in the timing of 
delivery, to diagnose distress. On the other hand, there is a 'wilder' body of work stimulated by the so called turn to affect. Wetherell has developed a notion of affective practice that:

focuses on the emotional as it appears in social life and tries to follow what participants do. It finds shifting, flexible and often over-determined figurations rather than simple lines of causation, character types, and neat emotion categories (2012, pp **).

In both cases it is possible to see discourse based work generating novel and analytically grounded studies in the domain of emotion, capturing the piquancy of the psychologically charged moment or painting in the sweep of ideological argument.

\section{A matrix of social psychological issues}

In this brief final section I will make some observations about the domain of social psychology. Some responses to Discourse and Social Psychology and the traditions of work that it generated suggested that it was interesting and yet more relevant in another discipline - linguistics or sociology, say, or even literary criticism. We can now see that far from having an only oblique relation to social psychology discourse work can claim to have made a profound contribution and has played a role in redefining the discipline. The work of Martha Augoustinos, Michael Billig, Margaret Wetherell and others on ideological matters and the way social organizations are legitimated and intergroup differences are disguised is now well established (see papers in Potter, 2007). Let me end by sketching the way more recent work offers a novel approach to social psychological matters.

Key here is the way discourse work and in particular recent discursive psychology deals with direct records of actual people interacting with one another in real time, and its analysis situates that interaction within the social, physical and institutional contexts of 
what is going on as these things become live and relevant in the interaction. It would be hard to argue against this being a core, maybe even foundational, domain for a distinctively social psychology.

Take the traditional social psychological field of social influence. Typical social influence work considered the operation of variables such as credibility, status and information on the behaviour of individuals. Discourse work has taken a rather different path that has considered concrete situations where something that might be seen as influence takes place; that is, where individuals attempt to change the behaviour of other individuals. Some form of influence is part of a range of practices that can be described using vernacular action descriptions such as requests, offers, admonishments, threats, complaints and advice. Studies of such practices have identified a range of often shared considerations that cut across the different practices.

Curl and Drew (2008) studied requests in environments such as afterhours medical services or call centres that manage non-emergency calls to the police. Requests are actions where one party is modifying the behaviour of another. They noted that requests are build differently according (a) to the displayed entitlement of the request issuer to receive what the request demands and $(b)$ to the contingencies the request recipient faces in delivering what is requested. Request forms thus become more presumptuous when the person requesting claims high entitlement and treats the recipient as likely to be able to comply with the request (low contingency). Thus 'I was wondering if...' prefaced requests display less entitlement than 'could you...' prefaced requests.

Craven and Potter (2010) extended this analysis to consider the nature of actions where one party directly directs the behaviour of another, using material from family mealtimes. A feature of these was that they did not use 'I was wondering if...' prefaces 
(which we might see in a call to an out of hours surgery where the caller is showing low entitlement to a home visit and orienting to the contingency of the doctor being able to perform such a visit). Neither did they use the kinds of constructions typical of requests that orient to the wants or abilities of the recipient - 'do you want to come to dinner', 'could you come over on Saturday'. Rather directives embodied no orientation to the recipients' desires or capacities: 'put that down', 'hold that with two hands'. There is also a subtle shift in the appropriate next action for a directive. While for a request the appropriate next action is acceptance for a directive it is compliance.

Now contrast both requests and directives with advice. Here again one party is managing the behaviour of another. Heritage and Sefi (1992) noted that advice is normative - it is offering a course of action that should be followed. As a social institution advice builds a stance of disinterest, in contrast to requests which orient to the needs or requirements of the person who has issued the request. Advice is also epistemically asymmetric - the advice giver builds themselves as more knowledgeable than the advice recipient. This asymmetry can be worked with in various institutional situations. For example, Butler and colleagues (2010) studied the way advice on a child support line was regularly delivered using interrogative grammar - 'have you thought about talking to a teacher'. Such constructions manage the asymmetry. The counsellor builds a picture of the caller's situation, but also provides a softened indication of appropriate action. This highlights a relevant and possibly appropriate action yet allows the child to follow the advice or not by fitting it to her or his particular circumstances. In contrast, Hepburn and Potter (2011b) consider situations on a child protection helpline where advice is being resisted. Callers may use the detailed knowledge of their situation to resist the advice while the Call 
Takers can use generic social work knowledge or broader idioms and commonplaces - 'your child's health has got to come first'; 'grown ups have got to be grown up'.

What we see then is that these actions, all of which involve some kind of behaviour modification or social influence, orient to a set of core dimensions, notably entitlement, contingency, relative knowledge and the interests of the parties. All of these are live, oriented to, and relevant at different points as the practices unfold. The lexical and grammatical resources of a language, the different possibilities for delivery, and the physical affordances of the environment are used to build the specific action with specific implications for the recipient. Crucially, they are not factors that exert a simple causal influence; they are dimensions that participants orient to as they build their activities and respond to activities of others. This, this is the start of a possible matrix for understanding core issues in a social psychology that is built up from observation of 'everyday lives, as they happen' (Stokoe, 2011b).

\section{CONCLUSION}

This paper has used the opportunity provided by the BJSP special issue to consider some of the themes as they have emerged in the last quarter century. In particular, it has focused on a range of critical points raised by both experimental and qualitative social psychologists of various traditions and providing a contemporary response. This has focused in particular on a range of misunderstandings and confusions about the scientific basis of discourse work, the nature of observation, and the possibility of a systematic analysis of voluntary behaviour. Its methodological discussion considers the role of qualitative interviews, the importance of working with naturalistic records, the way in which 
reactivity can be managed, and how sampling and generalization can work in this tradition. Finally, it considers how new insights into the classic psychological topics of experience and emotion can be generated, and ended with a sketch of a matrix of dimensions that are fundamental for building actions of social influence such as requests and advice. The point is to trace the way that Discourse and Social Psychology has been a platform for a scientific, rigorous, naturalistic social psychology. That naturalistic social psychology is now well under way.

\section{References}

Antaki, C. \& Rapley, M. (1996). ‘Quality of life' talk: The liberal paradox of psychological testing. Discourse and Society, 7, 293-316.

Antaki, C., Billig, M., Edwards, D. \& Potter, J. (2003). Discourse analysis means doing analysis: A critique of six analytic shortcomings, Discourse Analysis Online, 1, [http://www.shu.ac.uk/daol/articles/v1/n1/a1/antaki2002002-t.html].

Atkinson, J.M. and Drew, P. (1979). Order in Court: the Organization of Verbal Interaction in Judicial Settings. London: Macmillan.

Attenborough, F.T., \& Stokoe, E. (2012, in press). Student life; student identity; student experience: Ethnomethodological methods for pedagogical matters. Psychology, Learning \& Teaching.

Augoustinos, M., Tuffin, K. and Rapley, M. (1999) ‘Genocide or a Failure to Gel? Racism, History and Nationalism in Australian Talk', Discourse \& Society 10: 351-78. 
Bales, R. F. (1950). Interaction process analysis. Cambridge, MA: Addison- Wesley.

Barker, R.G. (1968). Ecological psychology: Concepts and methods for studying the environment of human behavior. Stanford, CA: Stanford University Press.

Berger, P.L., \& Luckmann, T. (1966). The social construction of reality. Garden City: Doubleday.

Bolden, G.B. \& Robinson, J.D. (2011). Soliciting accounts with Why-interrogatives in conversation, Journal of Communication, 61, 94-119.

Billig, M. (1992). Talking of the Royal Family. London: Routledge.

Billig, M. (1999) Freudian repression: Conversation creating the unconscious. Cambridge; Cambridge University Press.

Brown, S.D., Cromby, J., Harper, D.J., Johnson, K. \& Reavey, P. (2011). Researching "experience": Embodiment, methodology, process, Theory \& Psychology, 21, 493515.

Butler, C., Potter, J., Danby, S., Emmison, M. \& Hepburn, A. (2010). Advice implicative interrogatives: Building 'client centred' support in a children's helpline, Social Psychology Quarterly, 73, 265-287.

Byrne, R.W. \& Whiten, A. (Eds)(1989). Machiavellian intelligence: Social expertise and the evolution of intellect in monkeys, apes, and humans. Oxford: Oxford University Press

Clayman, S. \& Heritage, J.C. (2002). The News Interview: Journalists and public figures on the air. Cambridge: Cambridge University Press.

Coulter, J. (1979). The Social Construction of Mind: Studies in Ethnomethodology and Linguistic Philosophy. London: Macmillan.

Coulter, J. (2008). Twenty-five theses against cognitivism, Theory, Culture and Society, 25, 19-32. 
Craven, A. \& Potter, J. (2010). Directives: Contingency and entitlement in action, Discourse Studies, 12, 1-24.

Curl, T., \& Drew, P. (2008). Contingency and action: A comparison of two forms of requesting, Research on Language and Social Interaction, 41, 129-153.

Drew (2005). Is confusion a state of mind? In H. te Molder \& J. Potter (Eds). Conversation and cognition (pp. 161-183). Cambridge: Cambridge University Press.

Edwards, D. (1997). Discourse and cognition. London and Beverly Hills, CA: Sage.

Edwards, D. (1999). Emotion discourse, Culture \& Psychology, 5, 271-291.

Edwards, D. (2006). Discourse, cognition and social practices: The rich surface of language and social interaction. Discourse Studies, 8 (1), 41-49.

Edwards, D. (2007). Managing subjectivity in talk. In A. Hepburn \& S. Wiggins (Eds.), Discursive research in practice: New approaches to psychology and interaction (pp. 31-49). Cambridge, UK: Cambridge University Press.

Edwards, D. (2008). Intentionality and mens rea in police interrogations: The production of actions as crimes, Intercultural Pragmatics, 5, 177-199.

Edwards, D. and Potter, J. (1993). Language and causation: A discursive action model of description and attribution. Psychological Review, 100 (1), 23-41.

Edwards, D. \& Potter, J. (1999). Language and causal attribution: A rejoinder to Schmid and Fiedler, Theory \& Psychology, 9, 849-63.

Edwards, D. \& Potter, J. (2005). Discursive psychology, mental states and descriptions. In H. te Molder \& J. Potter (Eds). Conversation and cognition (pp. 241-259). Cambridge: Cambridge University Press.

Edwards, D., \& Stokoe, E.H. (2004). Discursive psychology, focus group interviews, and participants' categories. British Journal of Developmental Psychology, 22, 499-507. 
Elder-Vass, D. (in press). The Reality of Social Construction. Cambridge: Cambridge University Press.

Elms, A. C. (1975). The crisis of confidence in social psychology. American Psychologist, 30, 967-76.

Fiske, S.T. \& Taylor, S. E. (2008). Social Cognition: From Brains to Culture. New York: McGraw-Hill.

Frosh, S. \& Saville Young, L. (2008). Psychoanalytic approaches to qualitative psychology. In Willig, C. \& Stainton-Rogers, W. (Eds). The SAGE handbook of qualitative research in psychology. London: Sage.

Gergen, K. J. (1973). Social psychology as history. Journal of Personality and Social Psychology, 26, 309-20.

Gergen, K.J. (1985). Social constructionist inquiry: Context and implications. In K.J. Gergen and K.E. Davis (Eds.), The Social Construction of the Person. New York: SpringerVerlag.

Gilbert, G. N. \& Mulkay, M. (1984). Opening Pandora's box: A sociological analysis of scientists' discourse. Cambridge: Cambridge University Press.

Godfrey-Smith, P. (2003.). Theory and Reality: An Introduction to the Philosophy of Science. Chicago: Chicago University Press.

Hanson, R.N. (1958). Patterns of Discovery: An Inquiry into the Conceptual Foundations of Science. Cambridge: Cambridge University Press.

Harré, R. (1979). Social being: A theory for social psychology. Oxford: Basil Blackwell.

Harré, R. (1989). Language games and the texts of identity. In J. Shotter and K.J. Gergen (Eds.), Texts of Identity. London: Sage.

Harré, R. and Secord, P. F. (1972). The Explanation of Social Behaviour. Oxford: Blackwell. 
Henriques, J., Hollway, W., Urwin, C., Venn, C. and Walkerdine, V. (1998 [1984]). Changing the subject: Psychology, Social Regulation and Subjectivity (2nd Ed.). London: Methuen.

Hepburn, A. \& Bolden, G. (in press a) Transcription. In Stivers, T. And Sidnell, J. The Blackwell handbook of Conversation Analysis. Oxford: Blackwell.

Hepburn, A. \& Bolden, G. (in press b). Transcription for the social sciences. London: Sage. Hepburn, A. \& Potter, J. (2011). Designing the recipient: Some practices that manage advice resistance in institutional settings, Social Psychology Quarterly, 74, 216-241.

Hepburn, A. \& Potter, J. (2011). Threats: Power, family mealtimes and social influence, British Journal of Social Psychology, 50, 99-120.

Heritage, J.C. (2005). Cognition in discourse. In H. te Molder \& J. Potter (Eds). Conversation and cognition (pp. 184-202). Cambridge: Cambridge University Press.

Heritage, J.C. \& Raymond, J. (in press). Navigating epistemic landscapes: Acquiescence, agency and resistance in response to polar questions. In J-P de Ruiter (Ed.). Questions. Cambridge: Cambridge University Press.

Heritage, J. \& Sefi, S. (1992). Dilemmas of Advice: Aspects of the Delivery and Reception of Advice in Interactions between Health Visitors and First Time Mothers (pp.359-419) In P. Drew \& J. Heritage (Eds). Talk at Work. Cambridge: Cambridge University Press. Hollway, W. (2005). Commentary, Qualitative Research in Psychology, 2, 312-314.

Hollway, W. \& Jefferson, T. (2005). Panic and Perjury: A Psycho-social exploration of agency, British Journal of Social Psychology, 44, 1-18.

Holstein, J.A. \& Gubrium, J.F. (Eds)(2008). Handbook of constructionist research. New York: Guildford. 
Israel, J. \& Tajfel, H. (Eds)(1972). The context of social psychology: A critical assessment. London: Academic Press.

Jefferson, G. (2004). Glossary of transcript symbols with an introduction. In G.H Lerner (Ed.). Conversation Analysis: Studies from the first generation.

Amsterdam/Philadelphia: John Benjamins.

Manstead, A.S.R. (2008). Research methods in social psychology. In Hewstone, M., Stroebe, W. \& Jones, K. (Eds). Introduction to social psychology: A European perspective (4th Ed.). Oxford: Blackwell.

McGuire, W.J. (1973) 'The Yin and Yang of Progress in Social Psychology: Seven Koan', Journal of Personality and Social Psychology, 26: 446-57.

Mulkay, M., Potter, J. and Yearley, S. (1983) Why an analysis of scientists' discourse is needed. In K. Knorr-Cetina \& M. Mulkay, (Eds). Science Observed: Perspectives in the Social Study of Science (pp. 171-203). London: Sage.

Nightingale, D. J., \& Crombie, J. (Eds.) (1999). Social constructionist psychology: A critical analysis of theory and practice. Buckingham: Open University Press.

Parker, I. (1997). Discourse Analysis and Psycho-Analysis, British Journal of Social Psychology, 36, 479-495.

Pedersen, W.C., Denson, T.F., Goss, R.J., Vasquez, E.A., Kelley, N.J. \& Miller, N. (2011). The impact of rumination on aggressive thoughts, feelings, arousal, and behaviour, British Journal of Social Psychology, 50, 281-301.

Potter, J. (1996) Representing reality: Discourse, rhetoric and social construction. London; Sage.

Potter, J. (2002). Two kinds of natural, Discourse Studies, 4, 539-542. 
Potter, J. (Ed.)(2007). Discourse and Psychology: Volume II Discourse and Social Psychology. London; Sage.

Potter, J. (forthcoming). Discourse analysis and discursive psychology. In Camic, P. (Ed.). The handbook of research methods in psychology. Washington: American Psychological Association Press.

Potter, J. \& Edwards, D. (2012). Conversation analysis and psychology. In Stivers, T. \& Sidnel, J. (Eds). Routledge Handbook of Conversation Analysis. London: Routledge.

Potter, J. \& Hepburn, A. (2005a). Qualitative interviews in psychology: problems and possibilities, Qualitative research in Psychology, 2, 281-307.

Potter, J. \& Hepburn, A. (2005b). Action, interaction and interviews - Some responses to Hollway, Mischler and Smith, Qualitative research in Psychology, 2, 319-325.

Potter, J. \& Hepburn, A. (forthcoming). Eight challenges for interview researchers. J.F. Gubrium and J.A. Holstein (Eds)(forthcoming). Handbook of Interview Research (2nd Ed.). London: Sage.

Potter, J. and Wetherell, M. (1987). Discourse and Social Psychology: Beyond Attitudes and Behaviour. London: Sage. Potter, J. (2002). Two kinds of natural, Discourse Studies, 4, 539-542.

Potter, J. and Wetherell, M. (1995). Natural order: Why social psychologists should study (a constructed version of) natural language, and why they have not done so, Journal of Language and Social Psychology, 14, 216-222.

Potter, J., Stringer, P. \& Wetherell, M. (1984). Social texts and context: Literature and social psychology. London: Routledge \& Kegan Paul. 
Puchta, C. \& Potter, J. (2002). Manufacturing individual opinions: Market research focus groups and the discursive psychology of attitudes, British Journal of Social Psychology, 41, 345-363.

Raymond, G. (2003). Grammar and social organisation: Yes/no interrogatives and the structure of responding, American Sociological Review, 68, 939-967.

Schegloff, E. A. (1992). Repair after next turn: The last structurally provided defence of intersubjectivity in conversation, American Journal of Sociology, 98, 1295-1345.

Schegloff, E.A. (2004). Putting the interaction back into dialogue, Behavioural and Brain Sciences, 27, 207-208.

Schegloff, E.A. (2006). On possibles, Discourse Studies, 8, 141-157.

Schegloff, E.A. (2007). Sequence organization in interaction: Volume 1: A primer in conversation analysis. Cambridge: Cambridge University Press.

Schmid, J., \& Fiedler, K. (1999). A parsimonious theory can account for complex phenomena: A discursive analysis of Edwards and Potter's critique of nondiscursive language research. Theory \& Psychology, 9(6), 807-822.

Shotter, J. (1975). Images of man in psychological research. London: Methuen.

Silverman, D. (2011). Interpreting qualitative data, $4^{\text {th }}$ Ed. London: Sage.

Smith, J.A. (2005). Advocating pluralism, Qualitative Research in Psychology, 2, 309-312.

Smith, J.A. and Osborn, M. (2008). Interpretative phenomenological analysis. In J.A. Smith (Ed.). Qualitative psychology: A practical guide to methods (2nd ed.). London: Sage. (2nd ed)

Smith, L. G. E. \& Postmes, T. (2011). The power of talk: Developing discriminatory group norms through discussion. British Journal of Social Psychology, 50, 193-215. 
Speer, S.A. \& Hutchby, I. (2003). From ethics to analytics: Aspects of participants:

orientations to the presence and relevance of recording devices', Sociology, 37, 315337.

Stivers, T. and Hayashi, M. (2010). Transformative answers: One way to resist a question's constraints, Language in Society, 39, 1-25.

Stivers, T., Mondada, L. \& Steensig, J. (Eds)(2011). The morality of knowledge in conversation. Cambridge: Cambridge University Press.

Stokoe, E. (2009). "For the benefit of the tape": Formulating embodied conduct in designedly uni-modal recorded police-suspect interrogations, Journal of Pragmatics, $41,1887-1904$.

Stokoe, E. (2011a). Simulated interaction and communication skills training: The 'Conversation Analytic Role-play Method'. In C. Antaki (Ed.), Applied conversation analysis: Changing institutional practices. Basingstoke: Palgrave Macmillan.

Stokoe, E. (2011b). Social psychology and social interaction: Identities, simulation and application. Keynote presentation, British Psychological Society Social Psychology Section. Cambridge, September.

Stokoe, E., \& Edwards, D. (2010). Asking ostensibly silly questions in police interrogations (pp. 108-132). In A.F. Freed \& S. Ehrlich (Eds.), Why do you ask?": The function of questions in institutional discourse. Oxford: Oxford University Press.

Tajfel, H. (1972). Experiments in a Vacuum. In J. Israel \& H. Tajfel (Eds). The context of social psychology: A critical assessment. London: Academic Press.

Tileagă, C. (2005). Accounting for extreme prejudice and legitimating blame in talk about the Romanies, Discourse and Society, 16, 603-624. 
Tileagă, C. (2009). The social organization of representations of history: the textual accomplishment of coming to terms with the past, British Journal of Social Psychology, 48, 337-355.

Tileagă, C. (2010). Cautious morality: public accountability, moral order and accounting for a conflict of interest. Discourse Studies, 12(2), 223-239.

Tileagă, C. (2011). (Re)writing biography: Memory, identity and textually-mediated reality in coming to terms with the past, Culture \& Psychology, 17, 197-215.

Webb, E.J., Campbell, D.T., Schwartz, R.D., \& Sechrest, L. (1966). Unobtrusive measures: Non-reactive research in the social sciences. Chicago: Rand McNally.

Wetherell, M. (1998). Positioning and interpretative repertoires: Conversation analysis and post-structuralism in dialogue, Discourse and Society, 9, 387-412.

Wetherell, M. (2012). Affect and emotion: A new social science understanding. London: Sage.

Wetherell, M. and Potter, J. (1992). Mapping the Language of Racism: Discourse and the Legitimation of Exploitation. Hemel Hempstead: Harvester/Wheatsheaf and New York: Columbia University Press.

Wetherell, M., Stiven, H. and Potter, J. (1987). Unequal egalitarianism: A preliminary study of discourses concerning gender and employment opportunities, British Journal of Social Psychology, 26, 59-72.

Willig, C. (2001). Introducing qualitative research in psychology: Adventures in theory and method. Buckingham: Open University Press. 